Acta Technologica Agriculturae 4

Nitra, Slovaca Universitas Agriculturae Nitriae, 2014, pp. 105-108

\title{
TEMPERATURE RELATIONS OF SELECTED ENGINE OILS DYNAMIC VISCOSITY
}

\author{
Peter HLAVÁČ ${ }^{* 1}$, Monika BOŽlKOVÁ', Radmila PRESOVÁ \\ 'Slovak University of Agriculture in Nitra, Slovak Republic \\ ${ }^{2}$ Mendel University in Brno, Czech Republic
}

\begin{abstract}
This article focuses on temperature relations of dynamic viscosity for selected engine oils. The effect of temperature on new and used oil dynamic viscosity was investigated. Measurements were performed on three different motor oil samples. All the three motor oil samples were synthetic. The first oil sample was new, the second sample was used for 15,000 km, and the third sample was used for $30,000 \mathrm{~km}$. There were made two measurements of samples in one week. Dynamic viscosity was measured using a digital rotational viscometer Anton Paar DV-3P. The principle of measurement is based on the dependence of sample resistance to probe rotation. The results of measurements are shown as graphical relationships between dynamic viscosity and temperature. Decreasing exponential functions in temperature relationships were used for all the samples. The highest difference between the first and second measurement was observed in the new oil, and very small differences were found in other oils. Due to different types of oils and different stage of usage, the results could not be compared.
\end{abstract}

Keywords: engine oil, temperature, dynamic viscosity, relation

The role of lubrication is an important part in the field of tribology. The main role of lubrication is in smoothening the movement of one surface over another. Lubricants are commonly used for lubrication to reduce the friction and wear of surfaces in contact, and they ensure effective heat transfer due to good thermal conductivity. One of the single largest applications for lubricants in the form of motor oil is protecting internal combustion engines in motor vehicles and powered equipment. Most lubricants are liquids (such as mineral oils, synthetic oils, silicon fluids, water, etc.). The selection of lubricants is very important for a longer life of machine tools. To select an appropriate lubricant, it is necessary to know its properties, the lubrication system of applied machinery, conditions of machinery, and lubricant cost (Vasishth et al., 2014).

The most important rheological parameter for lubricants is dynamic viscosity as it also affects the tribological properties like friction between interacting surfaces and wear (Vasishth et al., 2014). The viscosity of the lubricant will affect the hydrodynamically lubricated parts of the engine whereas the presence of a friction modifier will reduce boundary friction in the engine (Taylor, 1997).

The knowledge of viscosity and other parameters behaviour of an engine oil as a function of its temperature is of great importance, especially when considering the running efficiency and performance of combustion engines (Kumbár et al., 2012).

Vasishth et al. (2014) studied the relationship between viscosity and temperature at different shear rates for multiple grades of three different categories of lubricants. They performed measurements in a temperature interval of $(20-50){ }^{\circ} \mathrm{C}$. They found out that all the samples behaved like Newtonian fluids in this temperature range and obeyed the Arrhenius equation with temperature. Five bio-edible oils were subjected to rheological evaluations by Wan Nik et al. (2005). The effect of temperature on changes of viscosity was proved, and it was also found that heating the oil would eventually shift the oil towards Newtonian behaviour. From all measured samples, the sunflower oil has the highest viscosity stability with respect to temperature. Conceição et al. (2005) state that heat treatment leads to a degradation of samples accompanied by an increase of viscosity, probably because of interactions with intermediary compounds.

Heavy crude oil and its mixture with light crude oil were investigated by Ghannam et al. (2012). Meriem-Benziane et al. (2012) investigated the rheological properties of light crude oil and its emulsions in order to obtain more knowledge about the rheological behaviour of oil flow in pipelines. Oil film thickness measurements made in the front main bearing of an operating engine were compared with rheological measurements made on a series of commercial and experimental oil blends by Bates et al. (1986). They obtained a good correlation from a multiple linear regression of film thickness as a function of both high-temperature, high-shear-rate viscosities and relaxation times.

This article deals with rheological properties that are very complicated characteristics of materials. It contains selected theoretical basics from rheology and rheological measurement method. Results are presented as temperature relations of dynamic viscosity in a temperature range of $(20-80){ }^{\circ} \mathrm{C}$ in Figures $1-3$. The coefficients of regression equations and coefficients of determination are summarized in Table 1.

Viscosity as one of the most important rheological parameters is defined as the resistance of a fluid to flow. The unit of dynamic viscosity in SI units is Pa.s. Viscosity changes with temperature. The difference in the effect of temperature on the viscosity of fluids and gases is related to the difference in their molecular structure. The viscosity of most of liquids decreases with increasing temperature. Theories have been proposed regarding the effect of temperature on the viscosity of liquids. According to the 
Eyering theory, molecules of liquids continuously move into vacancies (Bird et al., 2002).

This process permits flow but requires energy. Activation energy is more readily audible at higher temperatures, and the fluid flows easily. The temperature effect on viscosity can be described by an Arrhenius type equation:

$$
\eta=\eta_{0} e^{-\frac{E_{A}}{R T}}
$$

where:

$$
\begin{array}{ll}
\eta_{0} \quad-\text { the reference value of dynamic } & \text { viscosity } \\
E_{A} \quad-\text { activation energy } \\
R \quad-\text { gas constant } \\
T \quad-\text { absolute temperature (Figura } \\
\quad \text { and Teixeira, 2007) }
\end{array}
$$

Liquid molecules are closely spaced, with strong cohesive forces between them. The temperature dependence of viscosity can also be explained by cohesive forces between molecules (Munson et al., 1994). As temperature increases, these cohesive forces between molecules decrease and flow becomes freer. As a result, viscosities of liquids decrease as temperature increases. In liquids, intermolecular (cohesive) forces play an important role. Viscosities of liquids show little dependence on density, molecular velocity or mean free path. In most liquids, viscosity is constant up to a pressure of $10.134 \mathrm{MPa}$, but at higher pressures, viscosity increases with increasing pressure (Sahin and Sumnu, 2006).

\section{Material and methods}

In our measurements, we have compared three different engine oils. All the three motor oil samples were synthetic. The first oil sample was new, the second sample was used for $15,000 \mathrm{~km}$, and the third sample was used for $30,000 \mathrm{~km}$. Measurements of dynamic viscosity were performed by the digital rotational viscometer Anton Paar DV-3P in the temperature range of $(20-80){ }^{\circ} \mathrm{C}$. The principle of measuring by this viscometer is based on the dependence of sample resistance to probe rotation. A probe with signification R7 was used in our measurements. The frequency of probe rotation was $200 \mathrm{~min}^{-1}$. There were made two measurements of samples in one week.

Temperature dependences of dynamic viscosity can be described by decreasing exponential functions (2):

$$
\eta=A e^{-B\left(\frac{t}{t_{0}}\right)}
$$

where:

$$
t \quad \text { - temperature }
$$

\begin{tabular}{|c|c|c|c|}
\hline \multirow[b]{3}{*}{ First sample } & \multicolumn{3}{|c|}{ Regression equation (4) } \\
\hline & \multicolumn{3}{|c|}{ Coefficients } \\
\hline & A in $\mathrm{mPa} . \mathrm{s}$ & B [1] & $\mathbf{R}^{2}$ \\
\hline First measurement & 278.112 & 0.0136540 & 0.891912 \\
\hline Next measurement & 305.680 & 0.0132386 & 0.889440 \\
\hline Second sample & A in $\mathrm{mPa} . \mathrm{s}$ & B [1] & $\mathbf{R}^{2}$ \\
\hline First measurement & 264.978 & 0.0128897 & 0.960828 \\
\hline Next measurement & 259.709 & 0.0129360 & 0.953277 \\
\hline Third sample & A in $\mathrm{mPa} . \mathrm{s}$ & B [1] & $\mathbf{R}^{2}$ \\
\hline First measurement & 249.260 & 0.0169690 & 0.916812 \\
\hline Next measurement & 249.515 & 0.0125806 & 0.901726 \\
\hline
\end{tabular}

$t_{0}-1^{\circ} \mathrm{C}$

$A, B$ - constants dependent on the kind of material and on ways of processing and storing

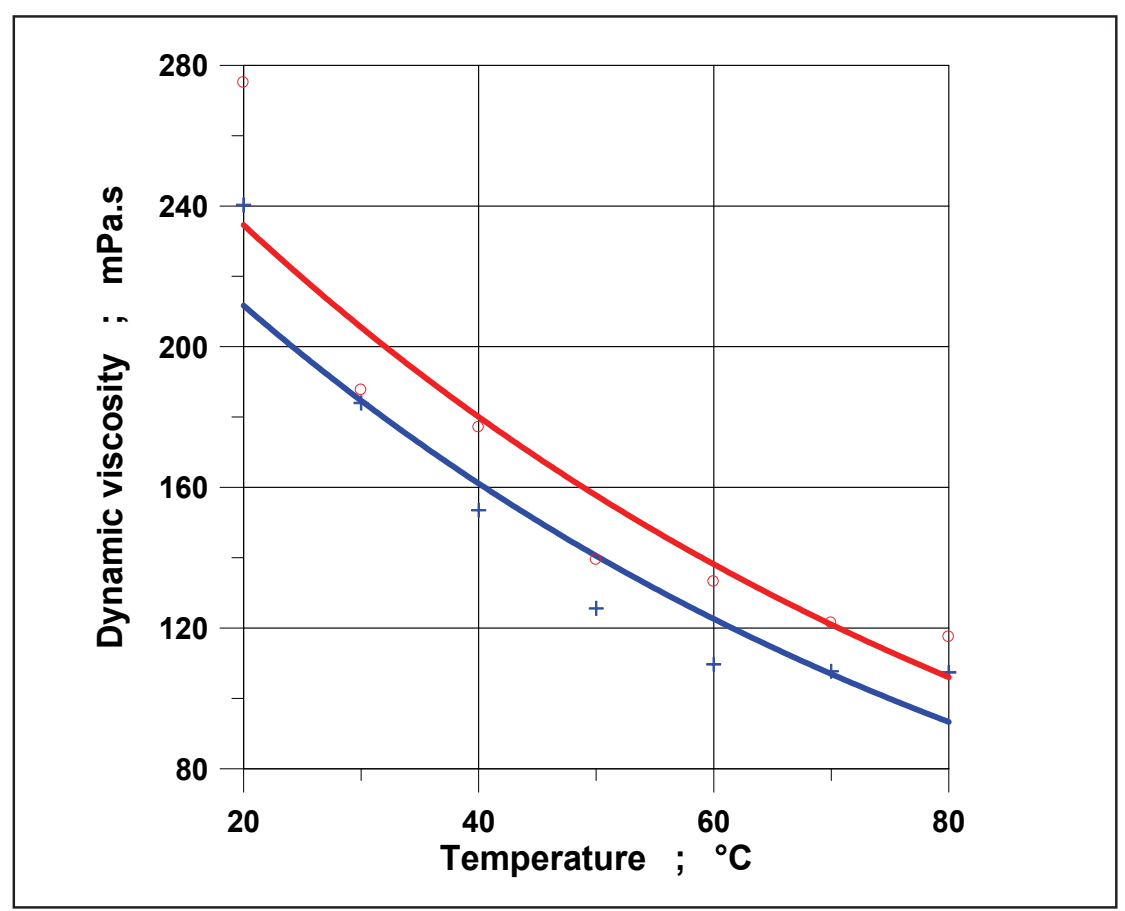

Figure 1 Temperature dependences of dynamic viscosity for the first sample First measurement $(+)$ and next measurement (o)

Table 1 Coefficients A, B of regression equation (4) and coefficients of determination $\left(R^{2}\right)$ 


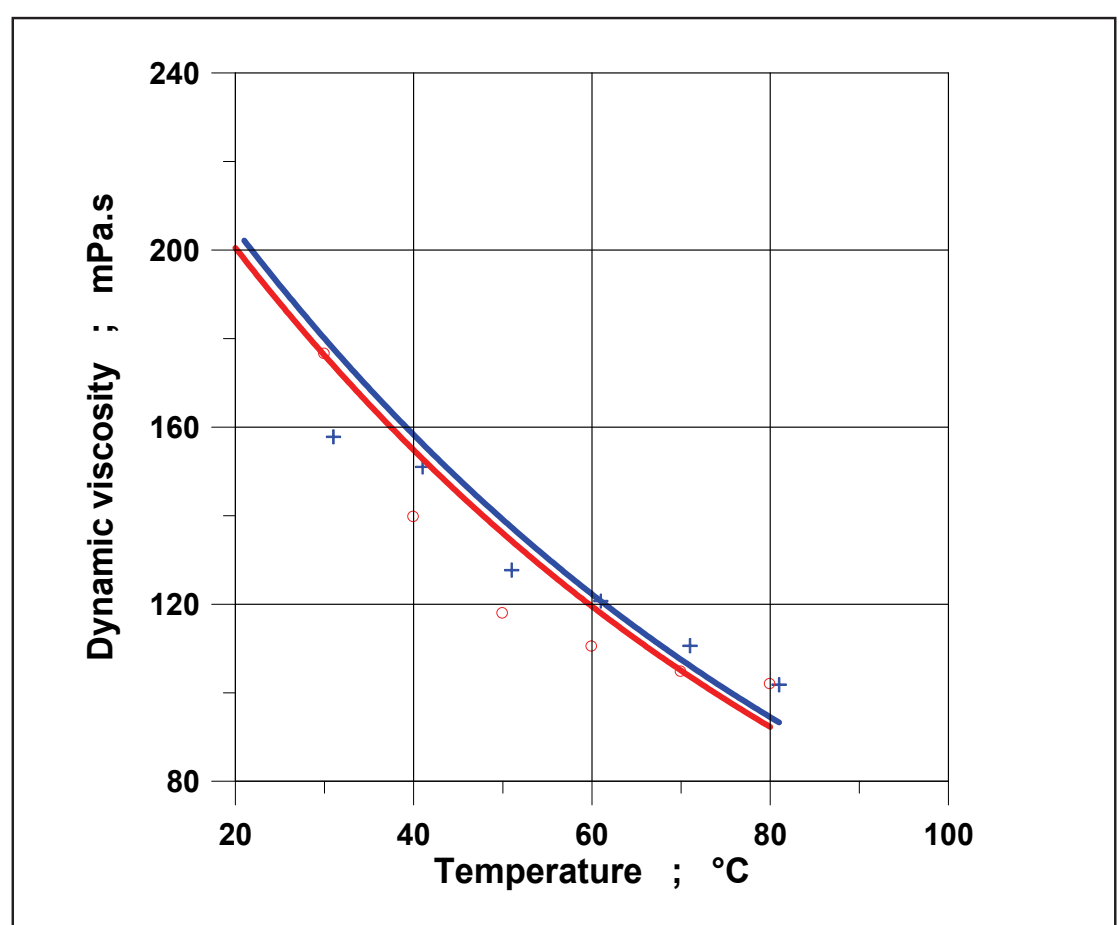

Figure 2 Temperature dependences of dynamic viscosity for the second sample First measurement $(+)$ and next measurement (o)

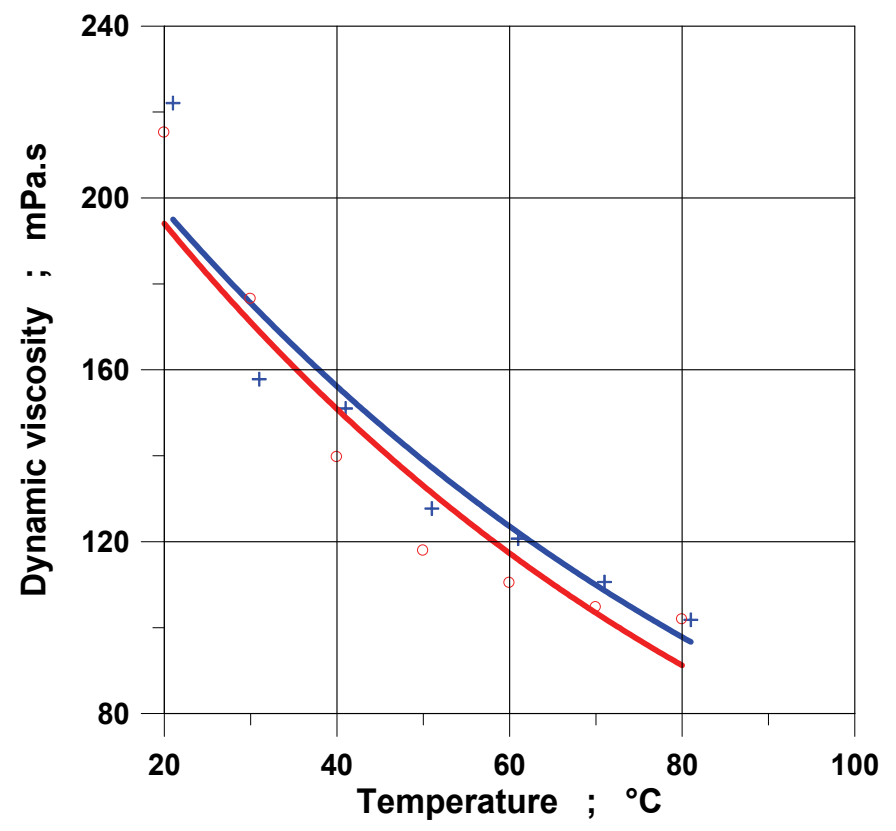

Figure 3 Temperature dependences of dynamic viscosity for the third sample First measurement $(+)$ and next measurement (o)

\section{Results and discussion}

Temperature dependences of dynamic viscosity for all the samples are shown in Figures 1-3. regression coefficients and coefficients of determination are shown in Table 1. Figures 1-3 indicate that the highest difference between the first and next measurement was observed in the new oil, and very small differences were found in other oils. Due to different types of oils and different stage of usage, the results could not be compared.

Table 1 shows that the highest coefficients of determination are for the second sample. The results could not be compared due to the fact that the samples used were different types of oils and were at different stage of usage.

\section{Conclusion}

Automatically controlled processes in manufacturing, handling and holding require exact knowledge about physical quantities of materials (Božiková and Hlaváč, 2013). To assure their quality, it is necessary to know their physical parameters, for example rheological properties (Božiková and Hlaváč, 2010). Rheological properties were measured by many authors.

The temperature dependences of all engine oils dynamic viscosities had a decreasing shape (Figures 1-3). We used exponential functions (Table 1) for all the relations of dynamic viscosity and temperature, which is in accordance with the Arrhenius equation (1). The highest difference between the first and next measurement was observed in the new oil, and very small differences were found in other oils. Due to different types of oils and different stage of usage, the results could not be compared.

\section{Acknowledgement}

This work was co-funded by the European Community under the project no. 26220220180 Building the 'AgroBioTech' Research Centre.

\section{References}

BATES, T. - WILLIAMSON, B. - SPEAROT, J. MURPHY, C. 1986. A correlation between engine oil rheology and oil film thickness in engine journal bearings. In SAE Technical Paper 860376, 1986. DOI: 10.4271/860376

BIRD, R. B. - STEWART, W. E. - LIHGTFOOT, E. N. 2002. Transport phenomena. New York : John Wiley \& Sons, 2002. 895 pp. 
BOŽIKOVÁ, M. - HLAVÁČ, P. 2010. Selected physical properties of agricultural and food products. Nitra : SUA, 2010. 178 pp. ISBN 978-80-552-0428-4.

BOŽIKOVÁ, M. - HLAVÁČ, P. 2013. Thermal conductivity and thermal diffusivity of biodiesel and bioethanol samples. In Acta Technologica Agriculturae, vol. 16, 2013, no. 4, pp. 88-92.

CONCEIÇÃO, M. M. - CANDEIA, R. A. - DANTAS, H. J. - SOLEDADE, L. E. B. - FERNANDES Jr., V. J. - SOUZA, A. G. 2005. Rheological behavior of castor oil biodiesel. In Energy Fuels, vol. 19, 2005, no. 5 , pp. 2185-2188. DOI: 10.1021/ef050016g

FIGURA, L. O. - TEIXEIRA, A. A. 2007. Food physics, Physical properties - measurement and applications. USA : Springer, 2007. $550 \mathrm{pp}$.

GHANNAM, M.T. - HASAN, S. W. - ABU-JDAYIL, B. - ESMAIL, N 2012. Rheological properties of heavy \& light crude oil mixtures for improving flowability. In Journal of Petroleum Science and Engineering, vol. 81, 2012, pp. 122-128. DOI: 10.1016/j. petrol.2011.12.024

KUMBÁR, V. - POLCAR, A. - ČUPERA, J. 2012. Rheological profiles of blends of the new and used motor oils. In Acta Universitatis Agriculturae et Silviculturae Mendelianae Brunensis, vol. 61, 2012, no. 1, pp. 115-122.

MERIEM-BENZIANE, M. - ABDUL-WAHAB, S. A. - BENAICHA, M. BELHADRI, M. 2012. Investigating the rheological properties of light crude oil and the characteristics of its emulsions in order to improve pipeline flow. In Fuel, vol. 95, 2012, pp. 97-107. DOI: 10.1016/j.fuel.2011.10.007
MUNSON, B. R. - YOUNG, D. F. - OKIISHI, T. H. 1994. Fundamentals of fluid mechanics. New York : John Wiley \& Sons.

SAHIN, S. - SUMNU, S. G. 2006. Physical properties of foods. USA : Springer, 2006. $257 \mathrm{pp}$.

TAYLOR, R. I. 1997. Engine friction: The influence of lubricant rheology. In Proceedings of the Institution of Mechanical Engineers, Part J: Journal of Engineering Tribology, vol. 211, 1997, no. 3, pp. 235-246.

VASISHTH, A. - KUCHHAL, P. - ANAND, G. 2014. Study of rheological properties of industrial lubricants. In Conference Papers in Science, 2014, article ID 324615, 5 pp. DOI: 10.1155/2014/324615

WAN NIK, W. B. - ANI, F. N. - MASJUKI, H. H. - ENG GIAP, S. G. 2005. Rheology of bio-edible oils according to several rheological models and its potential as hydraulic fluid. In Industrial Crops and Products, vol. 22, 2005, no. 3, pp. 249-255. DOI: 10.1016/j.indcrop.2005.01.005

\section{Contact address:}

Peter Hlaváč, Slovak University of Agriculture in Nitra, Faculty of Engineering, Department of Physics, Tr. Andreja Hlinku 2, 94976 Nitra, Slovak Republic, e-mail: Peter. Hlavac@is.uniag.sk 